\title{
El Área Metropolitana Gran Mendoza. Análisis de tendencias globales, factores endógenos y modelos de gestión del desarrollo urbano
}

\author{
Gran Mendoza Metropolitan Area, \\ Global Trends Assessment, Endogenous Factors \\ and Urban Development Management Models.
}

\begin{abstract}
A Área Metropolitana da Grande Mendoza. Análise de tendências globais, fatores endógenos e modelos de gestão do desenvolvimento urbano.
\end{abstract}

María Virginia Furlani CONICET

Argentina

\section{Resumen}

Difícilmente, en la actualidad, puedan concebirse a los territorios como meros espacios físicos, soportes de actividades productivas y de población. Evidentemente, son espacios dinámicos en los que impactan procesos sociales, políticos, económicos, culturales y ambientales, tanto globales como locales. En particular, las áreas metropolitanas son afectadas por graves problemas y disfuncionalidades que las hacen social y ambientalmente insostenibles. Diversas posiciones debaten respecto del carácter más o menos determinante de los factores exógenos y endógenos que transforman y definen, específicamente, las configuraciones urbanas. Este estudio trata de la ocurrencia de estos fenómenos en el área metropolitana argentina conocida como Gran Mendoza, de la provincia homónima, considerando, además, los modelos de gestión urbana predominantes y las innovaciones institucionales que el fenómeno suscita.

Palabras claves: metamorfosis urbana, tendencias globales, factores endógenos, Gran Mendoza.

\footnotetext{
María Virginia Furlani: Licenciada y Profesora en Ciencia Política y Administración Pública. Diploma Superior en Economía Política, Facultad Latinoamericana de Ciencias Sociales (FLACSO),Argentina. Doctoranda en Ciencias Sociales, con mención en Ciencias Políticas y Administración Pública de la Facultad de Ciencias Políticas y Sociales (FCPyS), Universidad Nacional de Cuyo (UNCuyo), Mendoza. Becaria interna de posgrado tipo II del Consejo Nacional de Investigaciones Científicas y Técnicas (CONICET),Argentina. <virgfurlani@hotmail.com>
} 


\begin{abstract}
Hardly, at present, can be designed to land, as mere physical spaces, supports productive activities and population. Obviously, they are dynamic areas that impact the social, political, economic, cultural and environmental, global and premises. In particular, metropolitan areas are affected by serious problems and dysfunctions that are socially and environmentally unsustainable. Different positions regarding the nature discussed more or less a determinant of exogenous and endogenous factors that transform and define specifically, the urban settings. We study the occurrence of these phenomena in the metropolitan area known as Gran Mendoza Argentina, also considering the prevailing models of urban management and institutional innovations that the phenomenon creates.
\end{abstract}

Keywords: metamorphosis urban, global trends, endogenous factors, Gran Mendoza

\title{
Resumo
}

Dificilmente, na atualidade, possam ser concebidos os territórios como meros espaços físicos, suportes de atividades produtivas e de população. Evidentemente, são espaços dinâmicos nos quais impactam processos sociais, políticos, econômicos, culturais e ambientais, tanto globais como locais. Em particular, as áreas metropolitanas são afetadas por graves problemas e disfunções que as tornam social e ambientalmente insustentáveis. Diversas posições debatem com relação ao caráter mais ou menos determinante dos fatores exógenos e endógenos que transformam e definem, especificamente, as configurações urbanas. Estuda-se a ocorrência desses fenômenos na área metropolitana argentina conhecida como Grande Mendoza, do Estado homônimo, considerando, além disso, os modelos de gestão urbana predominantes e as inovações institucionais que o fenômeno suscita.

Palavras-chave: metamorfose urbana, tendências globais, fatores endógenos, Grande Mendoza, 
El área metropolitana Gran Mendoza.Análisis de tendencias globales, factores endógenos y modelos de gestión del desarrollo urbano

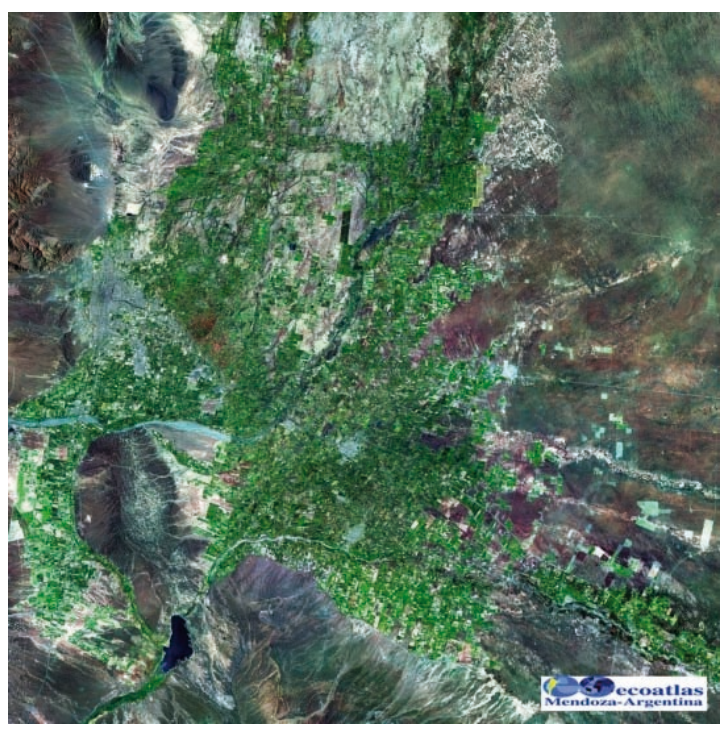

Imagen satelital del Gran Mendoza

EcoAtlas, octubre de 2005.

\section{Introducción}

En el presente trabajo se exponen consideraciones conceptuales y aproximaciones descriptivas que forman parte de la investigación de tesis doctoral Procesos sociopolíticos para el desarrollo urbano en municipios del Gran Mendoza, período 200 I a 2009.'

Se centra la atención en la descripción y caracterización del proceso de urbanización de la configuración territorial metropolitana Gran Mendoza, para lo cual se consideran cuatro dimensiones de análisis:

- El crecimiento y expansión física de la mancha urbana.

- $\quad$ El determinismo de las tendencias globales.

- Los condicionamientos de los factores endógenos.

- Los modelos de gestión del desarrollo urbano y las innovaciones institucionales.

I El trabajo de tesis se inscribe en la carrera de doctorado personalizado en Ciencias Sociales, con orientación en Ciencia Política y Administración Pública, de la Facultad de Ciencias Políticas y Sociales (FCPyS) de la Universidad Nacional de Cuyo (UNCuyo), y en las actividades de la beca de posgrado tipo Il, otorgada por el Consejo Nacional de Investigaciones Científicas y Técnicas (CONICET). Es dirigido por la Doctora Silvia Levín, docente e investigadora de la Universidad Nacional de Rosario, y codirigido por la Doctora Celia Duek, docente e investigadora de la FCPyS, UNCuyo. 
Ubicada en el oasis norte de la Provincia de Mendoza, al centro oeste de la República Argentina, el área metropolitana conocida como Gran Mendoza, compuesta por seis municipios incluida la ciudad capital provincial, concentra la mayor parte de la población y actividades de la región. La extensión de la mancha urbana avanza sobre una reducida superficie condicionada por las características físico-geográficas de desierto.

De esta manera, son altamente densificadas el área central y las pequeñas islas con características socioeconómicas homogéneas y segregadas, que se dispersan, fragmentadas y heterogéneamente, configurando un espacio discontinuo, desordenado. Se delinea un modelo polinodal de ciudades y de territorios que se relacionan con el centro histórico compacto a través de flujos de personas, movilidades y comunicación muy concentrados y congestionados.

En dicha organización territorial son evidentes los impactos de la explotación insostenible de los recursos naturales, sobre todo el suelo y agua y del uso limitado, ineficiente y crecientemente demandante de redes de infraestructura y servicios.

Ante estos desafíos, los actores locales promueven innovaciones institucionales para la gestión concertada de políticas públicas, que orienten los procesos de desarrollo urbano y la consiguiente puesta en valor de los territorios y sus recursos, de manera sostenible y equitativa.

En una primera fase del proyecto de investigación, se delimitan el enfoque teórico y los marcos conceptuales y analíticos desde los que se aborda el análisis de la problemática elegida. Se asumen factores de desarrollo local y urbano que enfatizan aspectos intangibles -prácticas políticas, estrategias de los actores, acuerdos básicos- facilitadores del desarrollo en su capacidad de articular, dinamizar y orientar un proyecto común que aglutine al territorio. Así, la unidad de análisis es la ciudad, en la medida que, a pesar de experimentar procesos de dispersión y fragmentación, las relaciones de proximidad física siguen conservando un papel esencial.

Desde esta aproximación, se consideran los fenómenos asociados al crecimiento y los cambios económico-productivos, socio-culturales y político-administrativos del área metropolitana. Es parte de la hipótesis central de trabajo: las configuraciones distintivas de desarrollo urbano del Gran Mendoza, en el período 200 I a 2009, responden a un modelo de crecimiento incipiente que fortalece la dimensión económica y la competitividad de algunos sectores, pero que, en términos de sustentabilidad del proceso de progreso local, no constituye un objetivo integral y compartido.

En este sentido, se avanza en la descripción multidimensional de la urbanización y metropolización del Gran Mendoza, así como de las problemáticas físicas, sociales, ambientales, políticas, infraestructurales, que implican transformaciones y tendencias cuantitativas y cualitativas, reseñadas a continuación.

En una última etapa (en desarrollo), se identifican instancias de consolidación de capital social en procesos sistemáticos y sostenidos de participación multiactoral, construcción de diálogos y canalización de las expresiones sectoriales, hacia la definición, por cierto, contradictoria, dinámica y compleja, del modelo de crecimiento urbano deseado. Se utilizan aquí metodologías cualitativas, a partir del relevamiento, 
sistematización y análisis de información lograda a través de entrevistas en profundidad a los principales referentes locales públicos y privados.

\section{Aspectos conceptuales para el análisis de las metamorfosis urbanas}

\section{I.Tendencias globales y procesos locales de expansión urbana}

Las sociedades atraviesan procesos de concentración de sus capacidades en el espacio geográfico más próximo, donde se producen las relaciones cotidianas: la ciudad. Es este, por consiguiente, el ámbito sobre el que se articulan los procesos de crecimiento económico, transformación social y construcción política, resultado de la interacción de múltiples actores (Barreiro, 2007; Boisier, 2003; Gallicchio, 2004; Rofman y Villar, 2006; Tomassini y Kliksberg, 2000).

Generalmente, las transformaciones urbanas y sus múltiples problemáticas se conciben como manifestaciones de los profundos y veloces cambios generados por las últimas revoluciones científico-tecnológicas, económicas y socioculturales (Castells, 1999). Así, se considera la década de los 70 el momento histórico en que los procesos de reestructuración económica e informacionalización de la sociedad impresionan en las ciudades (De Mattos, 2007), configurando metamorfosis urbanas de características cuantitativas y cualitativas novedosas.

Dado su contenido y alcance, algunos autores sostienen que se trata de una tercera revolución urbana (Ascher, 200I), en la que se destaca la sustancial modificación de las interacciones. De esta manera, cambia el modelo de organización territorial de relaciones verticales entre los centros y sus áreas de influencia y se configuran relaciones horizontales en redes y nodos (networks and hubs) ubicados en diversas partes del mundo (De Mattos, 2007).

En efecto, se desdibujan los límites geográficos y debilitan los vínculos tradicionales de cohesión interna que facilita la proximidad física, en la medida que las redes de nodos múltiples y los flujos -de capital, información, comunicación, personasatraviesan los territorios y conectan a los actores tecnológicamente a la distancia, en una geografia estratégica flexible motivada por innovaciones en el transporte y las comunicaciones (Dematteis, 2002; Sassen, 2007).

En este sentido, se deslocalizan, a nivel global, empresas y actividades en una economía mundial cada día más interconectada, que busca lugares estratégicos donde arribar los capitales móviles para ponerlos en valor. En la ponderación de los factores que se consideran para decidir cuál es el mejor lugar para invertir, indiscutiblemente, predomina la ortodoxia económica de minimización de costos de producción e incremento de la productividad.

Asimismo, son relevantes los condicionamientos y datos del contexto local y nacional en cuanto al marco jurídico, estabilidad, disponibilidad y calificación de 
recursos humanos, performance de los mercados financieros, capacidad científica y tecnológica, entre otros, como "factores de competitividad y atractividad de los capitales” (De Mattos, 2007, p. 9).

Esta lógica obliga a los territorios, por un lado, a generar estrategias que los conecten a la red global y, por otro lado, a poner en valor todos sus recursos y capacidades para ser influyentes dentro de la misma (Brugué et ál., 2002), para lo cual la gestión urbana se centra en acciones que incrementen la competitividad de las localidades. Desafíos que son encarados por sus gobiernos desde distintas perspectivas, en las que varía el rol y preferencias de los mismos.

Así, el modelo de gestión pública neutral y subsidiaria, característico de los años 90 , facilitó la toma de decisiones autónomas, por parte de las empresas, para la localización de sus inversiones, con escasa a nula consideración de las condiciones de sostenibilidad social y ambiental del territorio.

Justamente, los efectos negativos pronto se manifestaron, en el generalizado deterioro del medio ambiente -contaminación del aire y del agua, degradación del suelo, sobreexplotación de recursos naturales, residuos sólidos y peligrosos, entre otros-y la persistencia de las desigualdades sociales y de la fragmentación socioeconómica territorial.Así, solo "los sectores valiosos de los territorios y de la población se vinculan a las redes globales de creación de valor y apropiación de riqueza", mientras que "todos aquellos que carecen de valor (...) o que dejan de tener valor, se desconectan de la red y, en última instancia, se descartan" (Castells, 200I, p. I7I).

En las ciudades medias latinoamericanas, la metropolización expandida (De Mattos, 2007) cambia la configuración de la tradicional ciudad compacta de estilo europeo, hacia una ciudad dispersa (Hayes, 1976) de tipo norteamericano. Se trascienden las modalidades de desarrollo suburbano continuo y por adición de tejidos relativamente compactos. Entonces, se configura un esquema de periurbanización (Ávila, 200 I), vinculado al movimiento de la población de renta media y media-alta del centro hacia la periferia que busca lugares menos congestionados, con el consecuente despoblamiento de los núcleos centrales o desurbanización (Van den Berg, 1982).

Si bien los centros históricos y compactos de las ciudades latinoamericanas no han perdido su identidad y continúan aglutinando actividades y población, se observa la tendencia hacia la dispersión, con repartición de la concentración, expandiendo la mancha urbana hacia ciudades aledañas, en polos de jerarquía distinta (Dematteis, 1998).

En forma más o menos generalizada, el proceso se caracteriza por tener baja densidad, por la fragmentación, segregación y especialización monofuncional del espacio urbanizado, por el salpicado heterogéneo de localizaciones residenciales productivas y terciarias (European Environment Agency, 2006). La ciudad avanza sobre zonas rurales de la periferia, creando espacios desagregados y conectados por carreteras y tecnologías de comunicación e información que facilitan la movilidad y accesibilidad de las personas.

Siguiendo la tipificación que elabora Giampino (2010, pp. 53-55), la dispersión urbana describe algunas trayectorias diferenciales. En primer lugar, observa al suburbio residencial diseminado, compuesto de áreas residenciales de baja densidad, cuyos exponentes 
son los barrios cerrados o countries, desarrollados por inversores privados, unifamiliares, aislados, localizados entre núcleos urbanos y a lo largo de las directrices de transporte.

Estas áreas incluyen y conservan aquello que, entre otros aspectos, los motiva a dispersarse, es decir, algunos elementos rurales apreciados como jardines, parques y arboledas. Preferencias que fragmentan los ecosistemas por la sustracción de suelo a las actividades agrícolas y a las áreas naturales. El impacto es negativo en términos de consumo del suelo como recurso no reproducible y limitado y también en relación con los riesgos hidrogeológicos y el aumento de la contaminación, a causa del crecimiento de la movilidad privada.

Se observa que el suburbio residencial es interrumpido, en algunos casos, por la presencia de actividades comerciales, que, a su vez, configuran áreas de usos mixtos, zonificadas por funciones.

La definición de la periferia de franja o área residencial, caracterizada por una densidad mayor y localizada cerca de un centro alrededor del cual gravita, análogos a las adiciones periféricas de edificios residenciales públicos de los años 1960 y 1970.

Contempla, también, las áreas de uso comercial e industrial, que mantienen una estrecha relación con la viabilidad principal asumiendo configuraciones lineales o de bloque, dependiendo de factores claves como la accesibilidad, garantizada por el sistema infraestructural, el precio relativamente bajo de las áreas y las ventajas generadas por la economía de aglomeración.

Una de las problemáticas de la fragmentación socio-espacial es la privatización del terreno público residencial, recreativo, comercial, empresarial -asociado básicamente al acceso restringido a las zonas- y la mayor exigencia de infraestructura y servicios, que conlleva un incremento de los costos energéticos y una distribución desigual del equipamiento urbano. Esto último profundiza la acumulación de condiciones de diferenciación, adquiriendo cada espacio una significación social homogénea, que los diferencia en la heterogeneidad de actividades y población (Pírez, 200I).

\section{Gestión pública para el crecimiento y el desarrollo urbano}

En el apartado anterior se han descrito las tendencias globales que plasman en el territorio una particular configuración urbana caracterizada, en términos generales, por la dispersión y segregación socio-espacial. En este punto interesa reflexionar respecto de la fragmentación de los actores implicados en la gestión de espacios metropolitanos, resultado de la multiplicación de competencias territoriales y de los ámbitos jurisdiccionales y administrativos que se solapan.

Cabe destacar que las ciudades suelen tener poca autonomía y los financiamientos para el desarrollo permanecen en las administraciones públicas de niveles superiores, a través de políticas y programas. Precisamente, la discontinuidad característica de la ciudad dispersa representa un indicador de ineficiencia de este tipo de gestión, y evidencia la ausencia de coherencia territorial y de medidas de control.

Además, las orientaciones políticas de desregulación y descentralización de funciones y actividades de las administraciones estatales, enmarcan institucionalmen- 
te la ausencia de una estrategia general de desarrollo territorial (Camagni et ál., 2002), Por consiguiente, favorecen el crecimiento anárquico e ilimitado de urbanizaciones fragmentadas, como resultado de un proceso degenerativo de los sectores económico, cultural y social (Clementi et ál., 1996).

Como se mencionara en el apartado anterior, la búsqueda de competitividad de las ciudades conlleva, en muchas ocasiones, a que los gobiernos locales asuman las lógicas del mercado, descuidando la misión central del quehacer del Estado. De esta forma, las coaliciones políticas entre actores, enfatizan la promoción del desarrollo económico, la organización empresarial y la desregularización de la gestión urbanística y de los servicios públicos (Cuenya, 2004).

Desde esta postura, la política urbana se reemplaza por el marketing urbano, enfocando la acción pública local en determinados lugares, promoviendo el aumento de las rentas a través de la conquista de oportunidades de negocios en el territorio, siendo gestionados por sistemas independientes de sus gobiernos que tienen como referencias los patrones de desempeño de empresas privadas.

Se tiende a transformar el espacio público en vidriera de las ciudades, logrando mejor posición que el resto mediante la explotación de los recursos (energéticos, naturales, materiales), sin considerar la capacidad de carga de los sistemas. En consecuencia, se desplazan los derechos colectivos de desarrollo urbano por los derechos individuales de propiedad y beneficio.

Las ciudades que encuentran su razón de ser en las lógicas del mercado, pierden su base esencial de contacto, regulación, intercambio y comunicación, elementales en la interacción entre los ciudadanos y sus actividades e instituciones (Rueda, 2007). La planificación funcionalista y el interés comercial crean espacios exclusivos según los niveles de renta, desconectando el tejido social y desaparece el sentido que tiene la ciudad como una civis. La urbe se va vaciando de contenido, las relaciones vecinales, la regulación de comportamientos por conocimiento y afectividad, la identidad con el espacio, las probabilidades de contacto que ofrece el espacio público, se van diluyendo.

En esta instancia, entonces, cabe preguntar, ¿pueden los gobiernos locales intervenir en las tendencias globales que se imprimen en los territorios, estableciendo un modelo de gestión pública orientada al desarrollo sostenible y equitativo? Tal discusión es analizada por De Mattos (2002), en torno a la afirmación de que los cambios que experimentan las ciudades se asocian a los impactos de los procesos globalizados. Rescata opiniones que ponen en duda tal relación causal, frente a condicionamientos endógenos que tendrían más fuerza transformadora que la globalización. El autor concluye que existe evidencia acerca de que las metamorfosis de las urbes son debido a las tendencias globales, sin embargo, cada una preserva rasgos identitarios históricos, que permiten distinguir una ciudad de otra.

Asimismo, Dematteis (2006) remarca y discute la orientación analítica de la mayoría de los estudios que resaltan el carácter exógeno de las fuerzas que plasman la nueva realidad urbana, tanto física como social, en la síntesis del fenómeno global tecnológico y económico-financiero, autónomo y determinista que controla los sistemas socioterritoriales. 
Para el autor,"las transformaciones territoriales urbanas no son la consecuencia de cambios que suceden antes, en un hipotético sistema socio-político-económico separado del territorio (...)" sino que asume la hipótesis opuesta de que:

Nada se piensa, se hace, ni se cambia si no es a través de la materialidad de los lugares y de sus propiedades, porque es a través de estas - de las cosas ligadas al suelo- que pasan necesariamente (aunque no en modo determinista) todas las relaciones sociales y sus representaciones conceptuales (Deleuze y Guattari, 1991) (ibídem, p. 56).

Por consiguiente, sostiene que:

Como sistemas territoriales locales, las ciudades expresan formas de territorialidad distintas, según las relaciones que sus propios sujetos establecen con el territorio que, entendido como un milieu, es un conjunto de condicionesvínculos-recursos potenciales ligados a la naturaleza de los lugares y a su patrimonio, es decir, a las propiedades sólidamente adquiridas por estos en el largo plazo histórico (ibídem, p. 58).

En este sentido, los enfoques de desarrollo endógeno proclaman una sostenibilidad económica, referida a la generación de valor agregado de los recursos locales para la inserción positiva de los territorios en la globalización, que asegure, además, inclusión social y sustentabilidad, resultado de la interacción de múltiples actores (Barreiro, 2007).

Desde esta perspectiva, el aprovechamiento de los recursos depende, básicamente, de los aspectos intangibles, el capital social e institucional del territorio, es decir, del modo particular que los actores locales se organizan y acuerdan entre sí y con agentes de niveles de decisión ubicados en distintas escalas. Bourdieu, Coleman, North, Putman, Portes, Kaztman entre otros, destacan aspectos intersubjetivos como la pertenencia a un grupo, la red de relaciones, los lazos permanentes de confianza, que forman un activo social para el individuo y un atributo colectivo.

Sin embargo, aun cuando la interacción de los múltiples actores locales supone instancias de cooperación para la formación de proyectos colectivos (Fleury, 2005), la ciudad todavía es un ámbito de confrontación de valores y de intereses diversos entre los sujetos que promueven un tipo de metamorfosis urbana y los que no están de acuerdo y proclaman alternativas.

Frente a la búsqueda de mecanismos de concertación para definir y aplicar políticas y formas de gestión comprometidas y responsables, que tengan como objetivo prioritario mejorar la calidad de vida de toda la población, se plantean innovaciones comunitarias (Bradford, 2003). Las mismas pretenden lograr mejoras en la gestión de los asuntos urbanos, una profundización en la democracia participativa y una más efectiva satisfacción de las necesidades de la población (Méndez, 2009, p. 28). 
Al respecto, son variadas las herramientas de desarrollo local y nueva gestión pública que rescatan la relevancia de la interacción de actores públicos y privados, entre ellas la planificación estratégica, las estrategias participativas y la gestión asociada.

Particularmente, interesa considerar los planes de desarrollo -incluido el diseño de las estrategias, su ejecución y su evaluación- como catalizadores de voluntades públicas y privadas de diversas escalas, tanto cooperativas y conflictivas, de todos los actores que en la dispersión actúan. Constituyen un importante instrumento de coordinación e integración territorial hacia la racionalización del suelo, la previsión de zonas potencialmente edificables, la consecuente definición normativa que promuevan una compactación juiciosa, la reivindicación de las áreas libres, la protección de los espacios públicos, entre otros.

En particular, no porque el plan en sí mismo sea determinante del cumplimiento de objetivos planteados, sino por el proceso de reunión de actores con disímiles intereses y visiones del territorio deseado y los múltiples acuerdos y compromisos que implica. En esta línea, la programación no erradicará el proceso de dispersión, modalidad difícilmente planificable a través de los patrones tradicionales y habituales del urbanismo de la continuidad de los tejidos compactos y densos, propios de la ciudad consolidada, no obstante coadyuva en el encuentro de herramientas que lo controlen y dirijan, lo transformen y gobiernen.

Por tanto, la planificación del desarrollo alienta asumir una visión integral y coherente, frente a la persistencia de las antiguas fronteras políticas que dispersa también la atención entre los problemas de transporte, vivienda, empleo, ambiente y equidad social, pero difícilmente considera la dinámica urbana que subyace en ellos.

\section{Análisis de tendencias globales, factores endógenos y modelos de gestión del desarrollo urbano del Gran Mendoza}

Interesa en esta sección describir y caracterizar el proceso de urbanización de la configuración territorial metropolitana Gran Mendoza, sobre la base de los aportes teórico-conceptuales analizados precedentemente, referidos a:

- El crecimiento y expansión física de la mancha urbana.

- $\quad$ El determinismo de las tendencias globales.

- Los condicionamientos de los factores endógenos.

- Los modelos de gestión del desarrollo urbano y las innovaciones institucionales.

\section{El crecimiento y expansión física de la mancha urbana}

En la zona centro oeste argentina, en el oasis norte de la Provincia de Mendoza (ver figura 5), se extiende la mayor urbanización de la provincia y cuarta aglomeración en Argentina (censo 2010), el área metropolitana Gran Mendoza, definida como tal por ser 
un aglomerado compuesto por zonas urbanas que ocupan de manera total o parcial el territorio de dos o más gobiernos -locales-municipios (Pírez, 2008) (ver cuadro I y figura I).

Cuadro I Total de población

\begin{tabular}{|c|c|}
\hline \multirow{2}{*}{ Provincia } & Censo 2010 \\
\cline { 2 - 2 } & Total de población \\
\hline Total del país & $\mathbf{4 0 . 0 9 1 . 3 5 9}$ \\
\hline Buenos Aires & 15.594 .428 \\
\hline Córdoba & 3.304 .825 \\
\hline Santa Fe & 3.200 .736 \\
\hline Mendoza & 1.741 .610 \\
\hline
\end{tabular}

Fuente: Instituto Nacional de Estadísticas y Censos (INDEC).

Figura I

Mapa político, delimitación de las áreas urbanas más importantes y Manzanero Urbano del área metropolitana Gran Mendoza
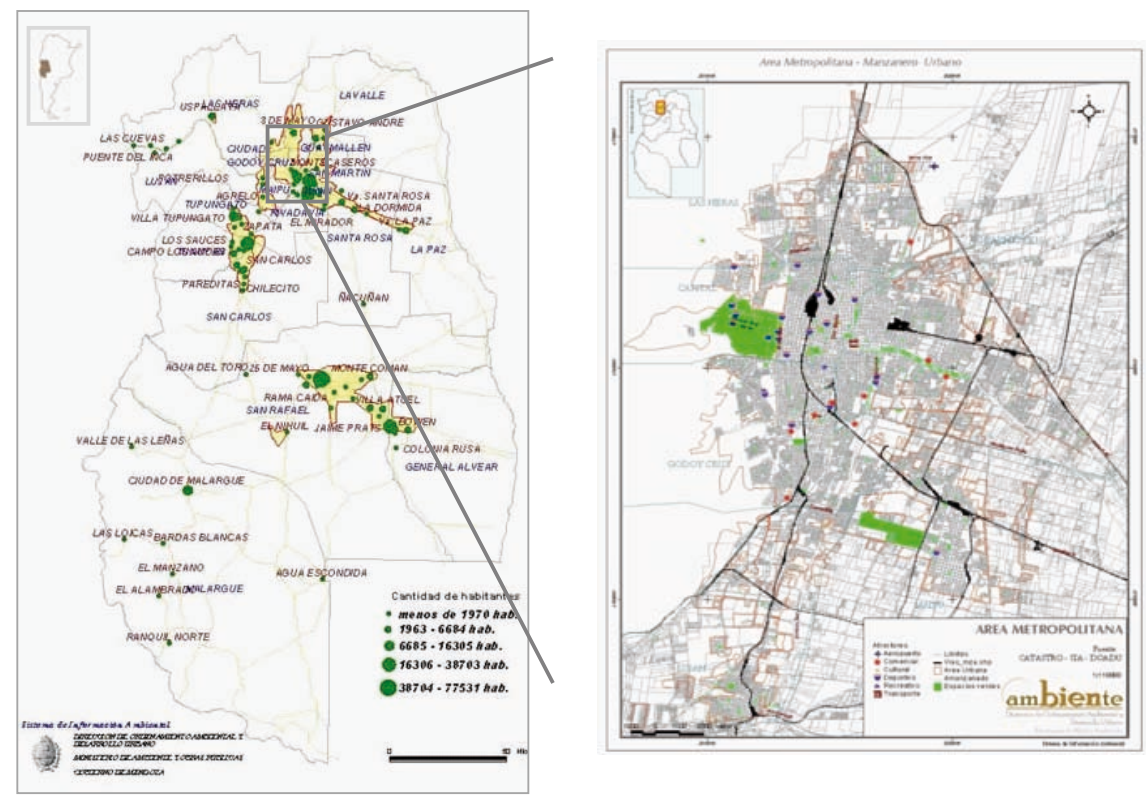

Fuente: Dirección de Ordenamiento Ambiental y Desarrollo Urbano (DOADU), Sec. de Medio Ambiente, Gobierno de Mendoza.

Como consecuencia de un proceso que comienza en la década de los 50 , la ciudad se expande desde el Departamento Ciudad de Mendoza, capital provincial, hacia los departamentos colindantes que, en diferentes momentos, se comportaron como 
satélites de la misma: Godoy Cruz, Guaymallén, Las Heras, Luján de Cuyo y Maipú. Evolución favorecida por la proximidad espacial de los mismos, estructurándose en forma lineal, siguiendo el eje Norte-Sur y hacia el Este, siguiendo las principales vías de comunicación sobre sectores agrícolas. Precisamente, las características geomorfológicas del territorio en el que se ubica el Gran Mendoza, limitan la expansión de la mancha urbana hacia el Oeste, si bien la ocupación de las frágiles áreas del piedemonte es una de las problemáticas más acuciantes ante los riesgos aluvionales (ver figura 2).

Figura 2

Riesgo natural. Piedemonte del Gran Mendoza.

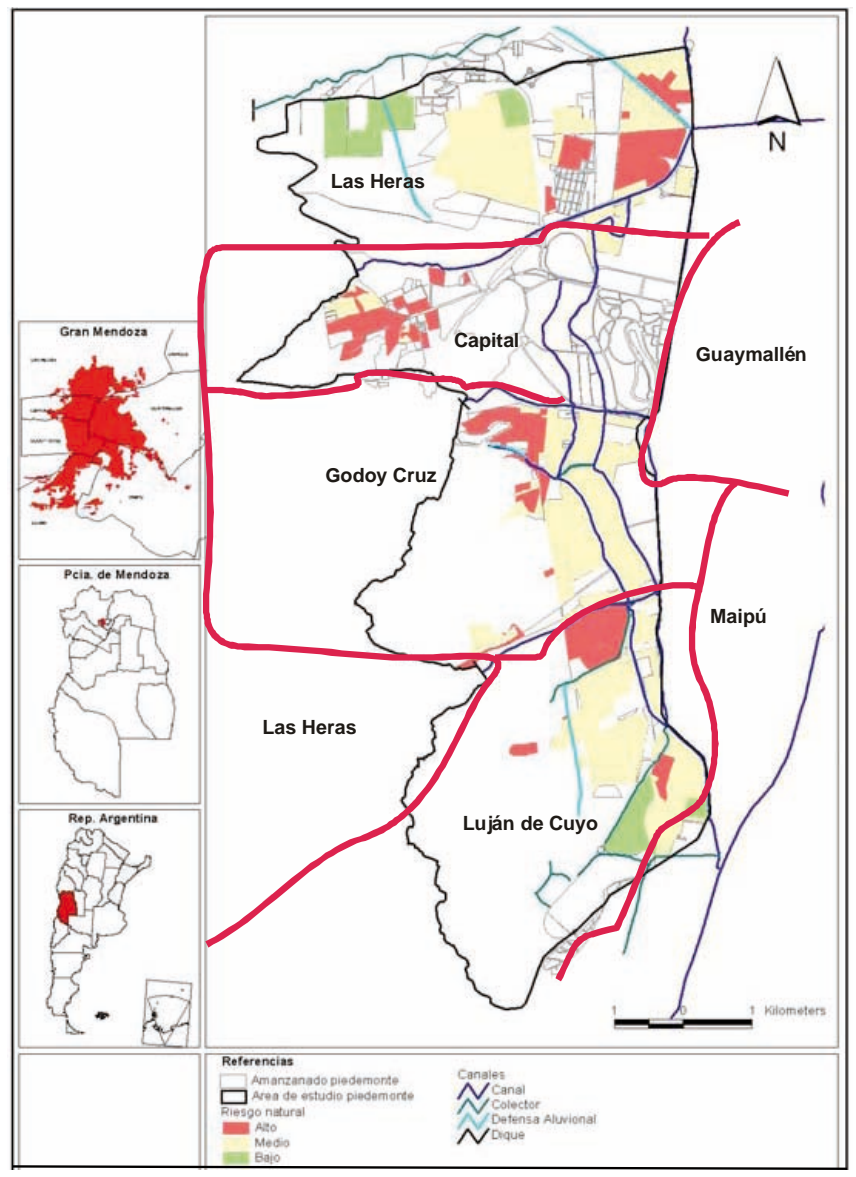

Fuente: Instituto CIFOT, FFyL, UNCuyo y IANIGLA, CRICyT

Las más cercanas están confundidas en el conjunto edificado, Ciudad Capital, Godoy Cruz, Guaymallén y Las Heras y las más lejanas, Maipú y Luján, mantienen, en parte, rasgos que las individualizan como centros urbanos con independencia espacial, que presentan la problemática del avance del proceso de urbanización sobre áreas 
con suelos de gran potencial agrícola (Furlani de Civit, 1999; Secretaría de Medio Ambiente de Mendoza, 20I0a).

Los departamentos restantes del mapa político provincial se dividen también en zonas, aunque agrupadas por una caracterización productiva y geográfica, distinta al proceso de metropolización del Gran Mendoza. Dichas zonas son: nordeste, compuesta por Lavalle, Santa Rosa y La Paz, Valle de Uco, que agrupa San Carlos, Tunuyán y Tupungato; Zona este, San Martín, Rivadavia y Junín; y el sur provincial conformado por San Rafael, General Alvear y Malargüe.

La despareja distribución de la población urbana entre los departamentos de la provincia se evidencia en el importante peso de la densidad de población promedio del Gran Mendoza que, de acuerdo a datos del censo 20l0, es de dos mil I73 hab/ km2 en los departamentos de Capital, Godoy Cruz y Guaymallén, representando la mayor superficie urbana (ver figura 3 ).

Figura 3

Mapa (I) Total de Población y Mapa (II) Densidad de Población de los Departamentos del Área Metropolitana Gran Mendoza.

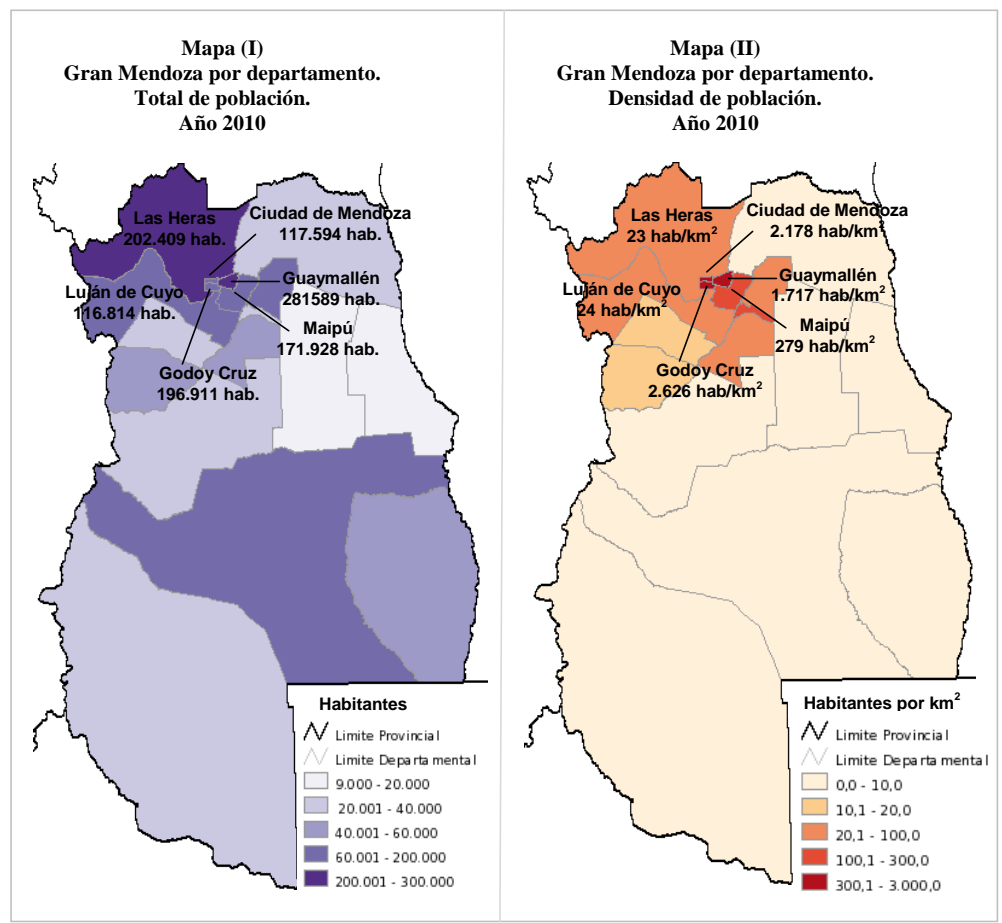

Fuente: Elaboración propia en base a imagen georreferencial y datos del Censo 2010, INDEC

La superficie total del Gran Mendoza, incluidos Maipú y Luján de Cuyo, es de I 4 mil 7 12 km2, representando un 10\% del total provincial. Sin embargo, esta superficie político-administrativa formal se observa sensiblemente reducida al considerar que la 
población y las actividades se instalan en el área de oasis, que cubre solo un $3 \%$ del total de la superficie provincial. Así, el reducido suelo irrigado alberga, al $62,5 \%$ de la población provincial, es decir, un millón 87 mil 245 habitantes (censo 2010) y, aproximadamente, el $65 \%$ del total de actividades económicas según datos de la Dirección de Estadísticas e Investigaciones Económicas (DEIE), Gobierno de Mendoza.

Un dato importante que aporta el último censo, es que la población de la Ciudad de Mendoza dejó de decrecer (entre los años 1991 y 200I la variación del crecimiento poblacional resultó negativo, siendo de $-8,7 \%$ ). Por el contrario, en la última década intercensal (años 200l-20l0), evidencia un 6\% de crecimiento positivo (INDEC, 20I0), aunque en términos generales el área metropolitana evidencia una desaceleración del ritmo de crecimiento causado por una baja progresiva de la tasa de natalidad, una tasa de mortalidad estable y una fuerte emigración de la población mendocina (ver cuadro 2 y gráfico I).

\section{Cuadro 2}

Evolución de la población y variación intercensal del crecimiento poblacional de los Departamentos del Gran Mendoza

\begin{tabular}{|c|c|c|c|c|c|c|c|c|c|}
\hline Departamento & $\begin{array}{c}\text { Población } \\
1970 \\
\end{array}$ & $\begin{array}{c}\text { Población } \\
1980 \\
\end{array}$ & \begin{tabular}{|c|} 
oblación \\
1991
\end{tabular} & \begin{tabular}{|c} 
Woblación \\
2001
\end{tabular} & \begin{tabular}{|c|} 
Población \\
2010 \\
\end{tabular} & $\begin{array}{l}\text { variacion } \\
1980-1970 \\
\end{array}$ & $\begin{array}{l}\text { variacion } \\
1991-1980 \\
\end{array}$ & $\begin{array}{l}\text { variacion } \\
\text { 2001-1991 } \\
\end{array}$ & $\begin{array}{l}\text { variacion } \\
2010-2001 \\
\end{array}$ \\
\hline Guaymallén & 138.479 & 181.456 & 221.904 & 251.339 & 281.589 & $31,00 \%$ & $22,30 \%$ & $13,30 \%$ & $12,00 \%$ \\
\hline Las Heras & 84.489 & 120.931 & 156.545 & 182.962 & 202.409 & $43,10 \%$ & $29,40 \%$ & $16,90 \%$ & $10,60 \%$ \\
\hline Godoy Cruz & 112.481 & 142.408 & 179.553 & 182.977 & 196.911 & $26,60 \%$ & $26,10 \%$ & $1,90 \%$ & $7,60 \%$ \\
\hline Maipú & 71.599 & 97.228 & 125.331 & 153.600 & 171.928 & $35,80 \%$ & $28,90 \%$ & $22,60 \%$ & $11,90 \%$ \\
\hline Capital & 118.560 & 119.088 & 121.620 & 110.993 & 117.594 & $0,40 \%$ & $2,10 \%$ & $-8,70 \%$ & $5,90 \%$ \\
\hline Luján de Cuyo & 47.074 & 62.118 & 79.952 & 104.470 & 116.814 & $32,00 \%$ & $28,70 \%$ & $30,70 \%$ & $11,80 \%$ \\
\hline Gran Mendoza & 572.682 & 723.229 & 773.113 & 986.341 & 1.087 .245 & $26,30 \%$ & $6,90 \%$ & $27,60 \%$ & $10,20 \%$ \\
\hline
\end{tabular}

Fuente: Elaboración propia en base a datos de los Censos Nacionales 1970, 1980, 1991, 2001 y 2010, INDEC

Gráfico I

Evolución de la población de los departamentos del Gran Mendoza.

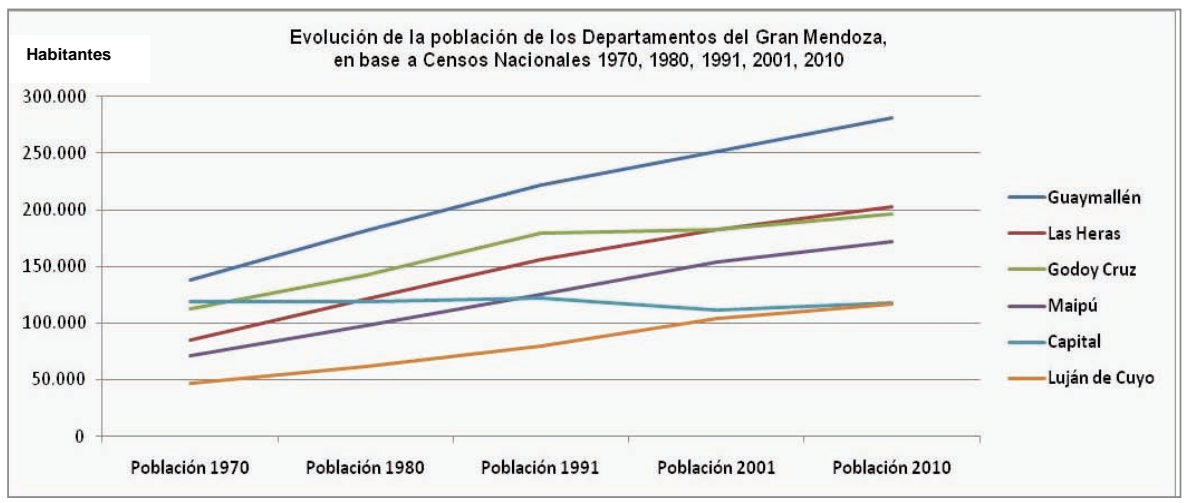

Fuente: Elaboración propia de acuerdo a datos de los censos nacionales 1970, 1980, 199I, 2001 y 2010, INDEC. 
Si se analiza el porcentaje de población urbana y su evolución en las últimas décadas, prevalece la emigración a las zonas urbanizadas, delineando trazos disímiles, en función de la capacidad física, económica y ambiental de cada uno de los municipios de contener a los nuevos pobladores. Por consiguiente, hace décadas que la población de la Ciudad Capital de Provincia y del Departamento de Godoy Cruz es 100\% urbana. Una verdadera metamorfosis demuestra Luján de Cuyo, departamento de características históricamente rurales, pero que en los últimos 40 años reflejó el fenómeno de la urbanización de lo rural (ver gráfico 2).

Gráfico 2: Porcentaje de población urbana según departamentos del Gran Mendoza. Años 1070, 1980, 1991, 2001.

\begin{tabular}{|l|r|r|r|r|}
\hline \multicolumn{5}{|c|}{$\begin{array}{c}\text { Porcentaje de población urbana según } \\
\text { Departamentos del Gran Mendoza } \\
\text { Años 1970, 1980, 1991, 2001 }\end{array}$} \\
\hline Departamento & 1970 & 1980 & 1991 & $\mathbf{2 0 0 1}$ \\
\hline Capital & 100 & 100 & 100 & 100 \\
\hline Godoy Cruz & 100 & 100 & 100 & 99,77 \\
\hline Guaymallén & 85,9 & 90,7 & 91,7 & 92,66 \\
\hline Las Heras & 83,6 & 84 & 94,9 & 94,41 \\
\hline Luján de Cuyo & 53,4 & 56,8 & 73,4 & 80,32 \\
\hline Maipú & 48,7 & 51,2 & 65,8 & 69,65 \\
\hline
\end{tabular}

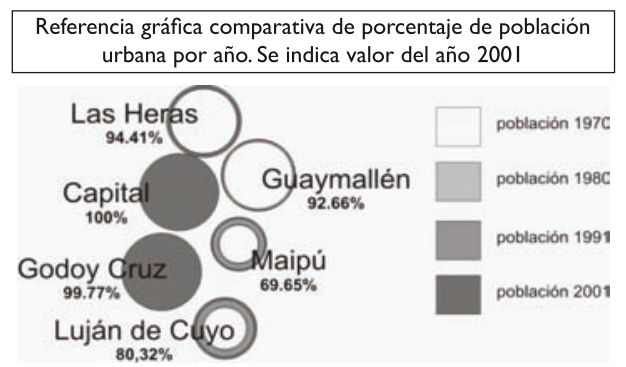

Fuente: Elaboración propia de acuerdo a datos de censos 1970, 1980, 1991, 200 I INDEC.

Tanto la emigración a las ciudades como la urbanización de áreas rurales se explican por múltiples causales, entre ellas el cambio de preferencias y estilos de vida de la población, la búsqueda de las mayores posibilidades educativas, servicios e infraestructura, y la terciarización de la economía con su impacto en el mercado de trabajo. Este último es de suma relevancia, ya que los cambios tecnológicos y productivos conllevaron procesos de reconversión agrícola e industrial e incremento del sector servicios, que se concentran en las áreas urbanas.

Sintetizando, el área metropolitana Gran Mendoza se extiende sobre una reducida superficie circunscrita por las condiciones físico-geográficas que empujan a la población y sus actividades a concentrarse en el área de oasis, sobre la que avanza el proceso urbanizador en forma alarmante. De esta manera, son muy densificadas el área central y las pequeñas islas que se dispersan en conjuntos planificados, con un uso limitado, ineficiente y crecientemente demandante de las redes de infraestructura instalada.

Se observa, entonces, una configuración territorial de interdependencias espaciales dispersas, flexible, fragmentada y heterogénea, pero demarcando zonas homogéneas. Así, se expresa como un espacio discontinuo, desordenado, en un modelo polinodal de ciudades y de lugares que se relacionan con el centro histórico compacto, altamente concentrado y congestionado.

Respecto del área residencial, retomando la caracterización de Giampino, la demanda de tierra para uso residencial, ya sea a través de planes de vivienda estatales, 
por inversiones privadas o por la instalación de asentamientos espontáneos, avanza, sobre todo, en el área de cultivo $y$, peligrosamente, sobre el piedemonte.

Dicho movimiento recrea en la periferia metropolitana la antinomia que tipifica a la Argentina de principios del siglo XXI: inclusión y exclusión, manifiesta en la fragmentación de un territorio urbano que combina enclaves globalizados y fracciones urbanos marginales.

El Informe desarrollo humano en Argentina: trayectos y nuevos desafios, elaborado por el Programa Nacional de Naciones Unidas, destaca que:

La segregación residencial plasma en el espacio urbano las desigualdades sociales, mientras que los grupos más pobres se ven relegados a territorios, saneamiento y villas miserias con menor cobertura de bienes y servicios, los más privilegiados se autosegregan en barrios cerrados o countries (PNUD, 20 I0, p. I I4).

Se aprecia la particular fuerza con que este fenómeno se manifiesta el Gran Mendoza, donde la segregación residencial se produce en un espacio menor, con una mayor subdivisión y una intensificación de las diferencias.

Así, por una parte, el suburbio residencial diseminado, caracterizado por áreas residenciales de baja densidad, es decir, los barrios cerrados o countries desarrollados por inversores privados, eligen como lugares preferidos para la residencia de las familias de clase media y alta, principalmente, el área próxima a Chacras de Coria,Vistalba, etc. en el Departamento de Luján de Cuyo, al sudoeste del Departamento de Guaymallén y de la Ciudad de Maipú. Otra alternativa es la zona del piedemonte (ej. barrio Dalvian), menos atractiva dadas las limitaciones de servicios y las obras aluvionales.

La clase media y media-baja elige zonas del este y el norte, en ocasiones aledaños a centros comerciales (ej. Carrefour de Guaymallén y Wall-Mart en Las Heras), donde, además, son más bajos los costos de urbanización, configurando áreas de usos mixtos (ej. complejo Palmares y Palmares Valley). En cuanto al microcentro, se espera que la Ciudad de Mendoza crezca en altura ante la falta de terrenos disponibles, al igual que en el Municipio de Godoy Cruz. En todos los casos, tras las preferencias individuales, el mercado es el asignador por excelencia del producto vivienda.

Del mismo modo, aunque por motivos y características totalmente distintas, ocupan la franja periférica los asentamientos inestables o villas. Concentrados en verdaderas áreas de segregación, estos asentamientos se distribuyen de forma irregular en los seis departamentos que conforman la aglomeración, aunque predominantemente en las franjas periféricas, en especial hacia el oeste, sobre el piedemonte de la precordillera.

Al año 2007 se registraban 85 asentamientos o villas en el Gran Mendoza, caracterizados por su grado extremo de pobreza y su falta de integración en el conjunto urbano, en el que habitan más de 50 mil personas. Cabe mencionar que estas cifras son volátiles, ya que dependen del contexto económico y las decisiones políticas (ej. de erradicación o reubicación), con lo cual, probablemente, los registros del censo 2010 muestren variaciones en el número de personas que habitan las villas, como 
ocurrió entre los años 1991 y 2007, en los que la cantidad de villas se mantuvo estable, sin embargo, disminuyó, en un 30\%, la cifra de hogares que las habitan (PNUD, 2009).

La búsqueda de empleos ante las sucesivas e históricas crisis económicas, sobre todo en el cinturón agrícola periurbano y en países vecinos, y el crecimiento de la pobreza y exclusión social, son algunos de los factores que motivaron la proliferación de las villas, contribuyendo a la expansión inorgánica de la masa edificada y de loteos ilegales, la mayoría desprovistos de infraestructuras y servicios (Gudiño de Muñoz, 2000).

En muchas ocasiones, la política habitacional destinada a estos sectores afianza el proceso de segregación e, incluso, de disminución de su calidad de vida por insuficiencia de servicios y medios de transporte. De esta manera, los espacios adquieren una significación social que los diferencia y tienden a acumular las condiciones de su diferenciación (Pírez, 200I). Las menores posibilidades educativas, su menor calidad materializada en la distribución desigual del equipamiento urbano y las infraestructuras, las dificultades en el acceso al mercado de trabajo, etc., generan un círculo vicioso que impide superar las dificultades.

Siguiendo con la tipología de Giampino, un $82 \%$ de las empresas e industrias se encuentran altamente dispersas en el área metropolitana, por lo que resultan insuficientes las zonas, áreas y parques industriales existentes, con el fin de conformar distritos económicos bastante compactos (ver figura 4).

Figura 4

Localización de las empresas industriales en el oasis norte

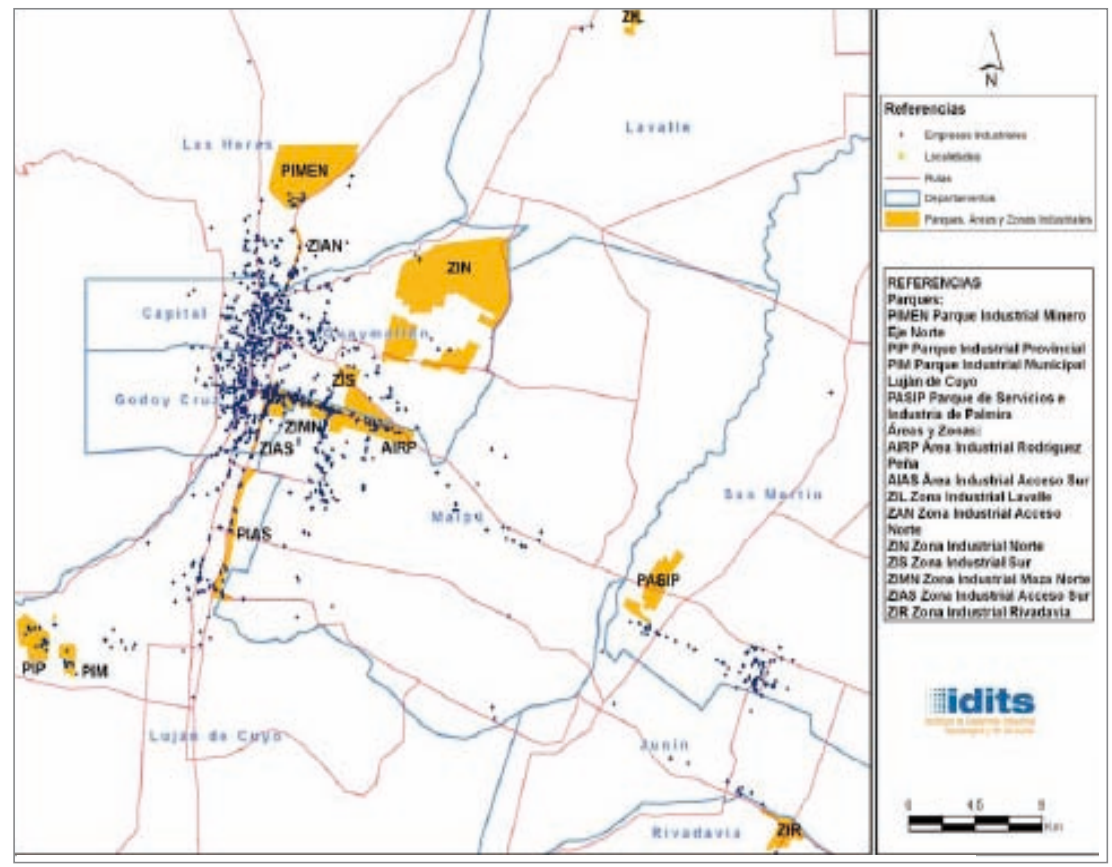

Fuente: Instituto de Desarrollo Industrial, Tecnológico y de Servicios de Mendoza (IDITS) 
La descripción realizada permite esbozar el modo en que se configura territorialmente la mancha urbana del Gran Mendoza y sus principales características y proyecciones. Así, mientras que la separación o dispersión es una de las características de la expansión urbana, la convergencia define el movimiento de flujos de personas y actividades hacia el centro histórico compacto de la metrópolis, en el corazón de la Ciudad de Mendoza. Por ser capital provincial concentra las actividades gubernamentales de los tres poderes en el conocido barrio cívico y oficinas dispersas en el denominado microcentro.

También agrupa gran parte de las sedes financieras, comerciales y empresariales, así como de las instancias educativas de nivel superior y científico-tecnológicas, nucleadas en el Centro Universitario del Parque General San Martín y, también, dispersas en el microcentro.

La elevada concentración de actividades en un espacio relativamente pequeño para albergarlas, convierte al centro histórico en un espacio anárquico de ingreso diario de gran número de trabajadores, estudiantes, ciudadanos en general. Se estima que unas 300 mil personas entran diariamente al microcentro, se movilizan el $50 \%$ en vehículos particulares, tan solo un $30 \%$ mediante un sistema de transporte público sobrecargado y el resto caminando o en bicicleta (Centro de Tránsito y Transporte, 2009).

Consecuentemente, la convergencia de flujos en el centro se aprecia en el diseño de las vías de comunicación y de transporte público (ver figura 5), sin adecuarse este último a la extensión de la expansión urbana hacia el sur y el oeste. La estructura radial de recorridos une el centro con cada punto de la periferia, es decir, cada recorrido parte del centro y vuelve al mismo punto. En muy pocos casos se unen puntos periféricos sin pasar por esta zona de la ciudad, solapándose los recorridos en algunas arterias del microcentro y provocando caóticos congestionamientos (García, 2010).

Figura 5

Red vial del Gran Mendoza

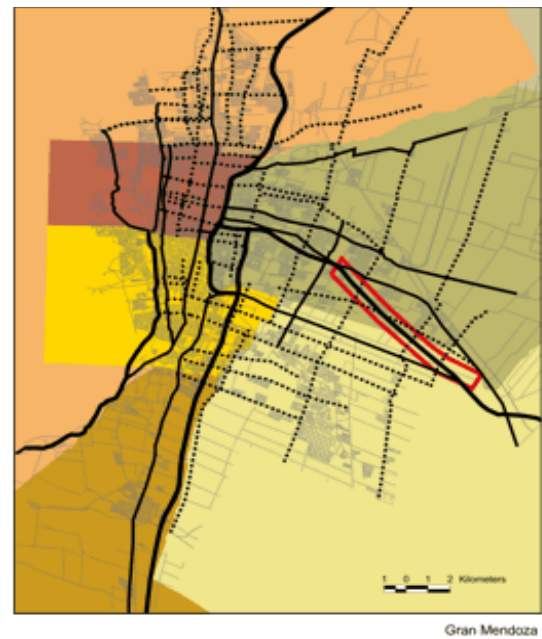

Fuente: CIFOT, FFyL, UNCuyo. 
Las contaminaciones sonoras y de aire deterioran la calidad del medio ambiente urbano, una de las causas principales de emigración de la población del microcentro hacia zonas abiertas y ambientalmente más saludables.

Sin embargo, en este punto interesa realizar un paréntesis para recuperar el dato del repunte del crecimiento poblacional de la ciudad de Mendoza en los últimos años. El mismo es revelador del cambio en las preferencias de la población en cuanto a la elección de su lugar de residencia, en especial de los jóvenes entre 35 y 45 años y adultos entre 56 a 65 años, de rentas media y media alta. Comienzan a buscar nuevamente edificios en el microcentro de la capital, atraídos por la cercanía a los lugares de trabajo y espacios de actividades sociales y culturales, como así también por las dificultades de la red de servicios para satisfacer a quienes optan por zonas alejadas.

La tendencia ha sido captada por las inmobiliarias, que rápidamente han multiplicado emprendimientos residenciales, incluso ofreciendo altas torres -permitidas por los gobiernos locales por vía de excepción a las normativas- que eran ajenas al paisaje edilicio de Mendoza. Este es justo el eje de la discusión actual en torno a la propuesta que realiza el Gobierno de la Ciudad de Mendoza modificatoria del Código de Urbanización vigente (aprobada el 21 de diciembre de 2010 y puesta en vigencia el 7 de enero del año 20II).

El objetivo general de la necesaria actualización legislativa propone favorecer el crecimiento de la densidad poblacional en el oeste del tejido urbano en zonas residenciales consolidadas, mejorar su eficiencia funcional y su situación presupuestaria.

Asimismo, dar respuesta a las problemáticas de (i) avance de la urbanización hacia zonas periféricas, extendiéndose sobre áreas productivas o sobre el frágil ecosistema árido regional y que resulta muy costoso por la consecuente extensión de infraestructura de servicios; (ii) presencia de áreas deprimidas con adecuadas instalaciones y alto potencial urbanístico disponibles para un uso más eficiente; (iii) el fuerte y desordenado incremento del tráfico vehicular en el centro urbano debido a la creciente evolución del mismo como foco de servicios; por tanto, (iv) mayor demanda de parques de estacionamiento y usos comerciales en áreas residenciales consolidadas; (v) aumento de los índices de contaminación atmosférica y sonora en la zona central (Bragagnini, 2009).

Desde la gestión municipal se afirma que el nuevo código fue elaborado en consulta técnica con entidades como el Colegio de Arquitectos, de Ingenieros y ONG, y se adapta a las características esenciales de la demorada Ley de Ordenamiento Territorial y Usos del Suelo, 805I/09. Así, plantea cinco estrategias para el logro de los objetivos: (i) densificación de áreas subutilizadas; (ii) recuperación de sectores deprimidos; (iii) desarrollo de nuevas centralidades; (iv) conservación de áreas residenciales y preservación de la calidad; y (v) patrimonio ambiental de la ciudad.

No obstante, ha motivado la movilización de vecinos y representantes de distintos sectores científicos, técnicos y profesionales que reclaman escasa participación en el proceso de elaboración y temor ante previsibles impactos negativos ambientales de los aspectos técnicos habilitados. Argumentan, además, que, en realidad, el objetivo de la norma es favorecer determinados proyectos inmobiliarios y 
darle discrecionalidad al municipio para aprobarlos. Entre ellos la edificación en altura condicionaría los recursos climáticos y el deterioro del paisaje urbano, en su valor de homogeneidad morfológica, sería duradero y difícilmente recuperable (Arboit et ál., 2010).Asimismo, se fundamenta que la política pública de desarrollo urbano de Mendoza no puede ser una decisión aislada de la consideración general metropolitana, ya que al tratarse de un continuo territorial, las decisiones y acciones de una de sus partes impactan y modifican al resto.

\section{El determinismo de las tendencias globales}

Reflejando la creciente globalización de los estilos de vida, las nuevas preferencias en las formas residenciales representadas por los barrios cerrados y exclusivos para grupos sociales con alto poder adquisitivo comúnmente denominados countries, ha agudizado el proceso de diseño diferencial del espacio (Furlani de Civit, 1999).

Constituyen verdaderos proyectos inmobiliarios de alta rentabilidad, ya que la gran demanda de terrenos para uso residencial genera un valor diferencial del suelo para nuevos loteos, muy dinámicos, la mayoría impulsados por desarrolladores urbanos, quienes normalmente llevan adelante diversos proyectos en diferentes localizaciones del área metropolitana, destinados a grupos socioeconómicos medios y altos, a veces asociados a centros comerciales, como es el caso del complejo Palmares.

En estos nuevos proyectos residenciales se plasman las tendencias culturales globales del consumismo individualista, que encuentra su expresión en la segregación buscada, voluntaria, una autosegregación local en un nuevo ámbito privado de contacto social con homogeneidad interna, motivada por la búsqueda de seguridad, privacidad, exclusividad, mejor calidad de vida, fácil acceso a servicios y centros comerciales (Schmidt, 2004).

Asimismo, conlleva la privatización del espacio público, impidiendo que las calles y los lugares de recreación sean usados libremente por todos los ciudadanos, favorecidos por la falta de regulación al respecto o la inobservancia por parte de la administración pública. En algunas ocasiones, los servicios públicos son reemplazados por los brindados por parte de empresas privadas y por reglamentaciones particulares que surgen del accionar de las asociaciones de propietarios o residentes de estos barrios cerrados (Roitman, 2000).

La zonificación de las áreas comerciales y los proyectos inmobiliarios son los pilares del modelo de desarrollo del Gran Mendoza, desde una perspectiva donde las transacciones comerciales prevalecen sobre las relaciones sociales y ponen en riesgo la frágil realidad del territorio. Las inversiones que se multiplican en los últimos 20 años en el espacio estudiado, carecen de un modelo de articulación que permita superar la lógica de crecimiento a una de desarrollo local integral, sostenible e inclusivo.

Desde que en Mendoza se construyó el primer centro comercial con características de mall, justamente el bautizado Mendoza Plaza Shopping en el año 1992, grandes proyectos comerciales se desarrollaron en el área metropolitana, contándose la decena en la actualidad, considerando aquellos que ya son proyectos aprobados. 
Ubicados de manera estratégica sobre ejes de máxima circulación, en áreas densamente pobladas a pocos kilómetros del centro, ofrecen ventajas atractivas a potenciales consumidores, como son la accesibilidad, la seguridad y el confort. Estos desarrollos imponen cambios drásticos en las estructuras de comercialización e implican no solo fuertes transformaciones en los patrones del consumo colectivo, sino también nuevas modalidades en el desarrollo de la vida cotidiana al reforzarse las localizaciones existentes en el interior del tejido urbano y creando zonas nuevas favoreciendo patrones de dispersión.

Este fenómeno se relaciona con una de las variaciones más dinámica, acelerada y fuertemente vinculada a la delimitación residencial de la ciudad, la renovación del centro comercial, donde se visualiza un área en la que predominan los servicios para la producción y otra dominada por comercios al servicio del consumidor (Furlani de Civit, 1999).

Una de las causas de la revitalización del microcentro es el boom turístico producido en los últimos años, consecuentemente, la construcción de hoteles cinco estrellas da respuesta a las necesidades de una clientela favorecida por la relación de cambio monetario. Esta tendencia se proyecta en la política del municipio de la ciudad que tiende a crear una imagen urbana que le permita competir para lograr la mayor afluencia de personas y capitales.

Finalmente, como ya se describiera , se evidencia un fenómeno de retorno de las poblaciones que antes emigraban hacia la periferia-barrios privados, ya que vivir en la ciudad es más eficiente en el consumo de los recursos no renovables y evita los traslados innecesarios, además de poder disfrutar de todos las ventajas propias de una urbe que ofrece todos los servicios. En respuesta, el gobierno local adhiere a la tendencia mundial orientada a recuperar las ciudades compactas.

\section{Los condicionamientos de los factores endógenos}

El principal condicionante del asentamiento humano y las actividades económicas es la peculiaridad de la geografía local, que, a su vez, resulta ser su rasgo identitario. El soporte físico del Gran Mendoza está dominado por la aridez del ambiente, con escasos recursos hídricos, vientos secos, aluviones, vulcanismo y sismicidad. Por ellas es que la principal metrópolis del oeste argentino nace de pautas socio-históricas que dieron lugar a un estilo propio de crecimiento y desarrollo: la cultura del agua y el compromiso con la tierra, recurso básico fundamental a proteger, y su empleo y distribución justa y equitativa, resultan vitales para la sociedad local.

La mayor proporción de superficie de Mendoza se identifica por la aridez de sus suelos, tal es así que el $97 \%$ del territorio está constituido por una zona desértica (ver figura 6). Estas condiciones físicas fragmentan al territorio en oasis, es decir, en espacios irrigados en torno a ríos y cuencas subterráneas, que concentran, en el $3 \%$ del espacio restante, $90 \%$ de la actividad económica y de la población provincial. Solo un $20 \%$ de los habitantes vive en zonas rurales o desérticas. 
Figura 6

Mapa de oasis de la Provincia de Mendoza.

Ubicación del Gran Mendoza

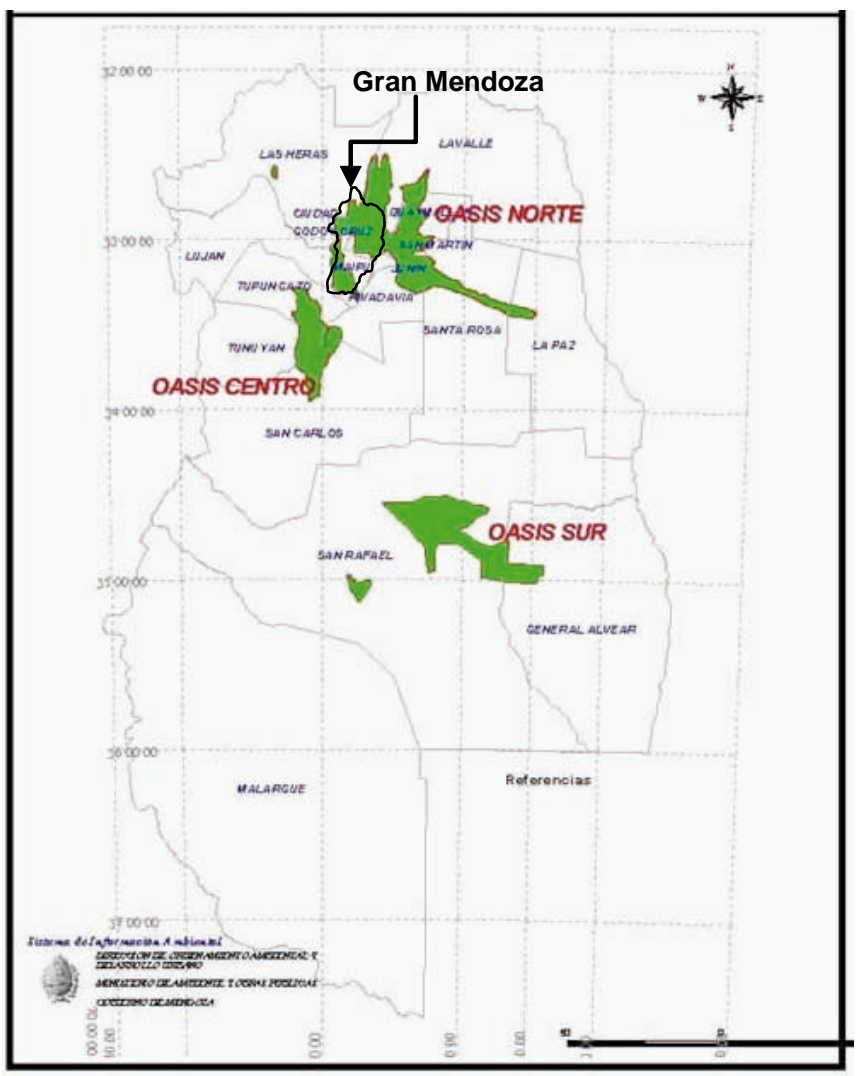

Fuente: DOADU.

El recurso hídrico resulta, por lo tanto, imprescindible tanto para el sustento humano como de insumo para el desarrollo del sector agroindustrial, de gran importancia económica local, tal es el caso del sector vitivinícola, una de las principales y más tradicionales actividades productivas de la provincia.

El agua es un recurso crítico y su escasez se acentúa con el crecimiento poblacional, que demanda un mayor nivel de consumo que la disponibilidad hídrica del oasis, actualmente de un nivel muy por debajo de lo requerido.Así, cada año, en especial durante la temporada primavera-verano, la población sufre cortes del elemental recurso. Incluso a fines del año 2010 se declaró el estado de emergencia hídrica, avanzando la gestión pública provincial en el control del uso del agua en las residencias. 
Asimismo, vientos secos, vulcanismo y sismicidad aumentan la fragilidad del territorio. En particular, en el Gran Mendoza se incrementa el riesgo aluvional por el accionar del hombre sobre un terreno sumamente frágil: el piedemonte, ya que la mancha urbana ha crecido también hacia esa zona.

Por una parte, la urbanización rural, los cambios en el mercado de trabajo, el crecimiento demográfico y de población urbana de las últimas décadas, la desvalorización productiva de la tierra, en especial de áreas frágiles como las faldas de cerros no irrigados y áreas marginales semiáridas. Por otra parte, el cambio de preferencias de sectores económicos medios y altos que optan por espacios más saludables y seguros donde residir, lo que implica un fuerte consumo de superficies, pues las parcelas habitualmente tienen grandes dimensiones y suelen incluir amplios espacios verdes comunes.Ambos, son causales endógenos que impulsan la extensión urbana sobre las áreas irrigadas rurales y las explotaciones agrícolas.

La Secretaría de Medio Ambiente del Gobierno de Mendoza alerta que, en la última década, se han perdido unas 5 mil hectáreas de áreas rurales con tierra productiva para diferentes actividades agrícolas, como consecuencia del avance urbano. Se generan, por lo tanto, áreas no planificadas sin atención de los impactos físico-territoriales y ambientales, tales como destrucción de la vegetación, pérdida de la calidad del suelo, falta de agua, riesgo de aluviones y fallas sísmicas.

En el Gran Mendoza es donde más se advierte el proceso y los más afectados son Guaymallén, Luján y Maipú. Por ejemplo, el área comprendida por los distritos de La Puntilla, Chacras de Coria,Vistalba y Las Compuertas, presentaba a comienzos de la década del 70 características eminentemente rurales. El $97 \%$ de la superficie estaba destinado a la agricultura, especialmente al cultivo de la vid, mientras que hacia el año 2000 solo el $60 \%$ de la superficie era agrícola y algunos distritos ya habían cambiado toda su fisonomía de rural a urbana.

Por consiguiente, la desordenada expansión del proceso de urbanización ligado a la gran concentración y densidad poblacional, conlleva riesgos de índole natural, social y económica y una acentuada pérdida de la calidad de vida de muchos sectores: elevada tasa de desempleo; inseguridad; segregación y desequilibrio urbano; congestión de las infraestructuras; sobreexplotación de los usos del suelo; degradación del medio ambiente citadino, contaminación del agua por efluentes líquidos y sólidos, escasez de espacios verdes, déficit en la gestión de residuos sólidos, peligrosos y patológicos, entre otros (Consejo Asesor Permanente, 2006).

\section{Los modelos de gestión del desarrollo urbano que predominan y las innovaciones institucionales}

Analizar el modelo de gestión de cada gobierno local que constituye el Gran Mendoza, de las relaciones intergubernamentales entre sí y con niveles superiores de gobierno, como así también las relaciones con la sociedad civil en la definición de políticas públicas requeriría mayor extensión del trabajo que la aceptada. Por lo tanto, se esbozan las principales observaciones de tan relevantes aspectos. 
Se parte de la consideración del suelo como bien público sujeto de gestión y control y no de fuerzas inmanejables. Por lo tanto, las políticas públicas son fundamentales en la organización y distribución del terreno. Sin embargo, tal como se analizara anteriormente, el paradigma de gestión subsidiario, desregulador y limitado de los años 90, perpetuó la ausencia de una estrategia de desarrollo territorial, favoreciendo el crecimiento urbano desordenado, privado y excluyente del Gran Mendoza.

En cierta medida, de acuerdo a expresiones de los propios actores locales públicos y privados, durante los últimos 20 años se apreció con benevolencia la multiplicación de desarrollos inmobiliarios. Contexto sinónimo de atracción de inversiones y competitividad territorial, en el que toda organización, incluida la administración local, es proveedora de productos y servicios para el mercado y los modelos de intervención para el desarrollo son centrados en la demanda, ignorando otros aspectos de la realidad social como la conservación de los recursos naturales.

Junto a esto, uno de los principales obstáculos que se observa es la dificultad para articular entre los gobiernos locales que conforman el Gran Mendoza, entre estos y el gobierno provincial, como así también entre las instancias gubernamentales y la sociedad civil. Dificultades reflejo de la realidad político-administrativa de Argentina, en la que predominan modalidades de gestión pública centralista y estadocéntrica. Es decir, el actor público preponderante es el Estado nacional, el rol de los gobiernos locales, a pesar de los avances, continúa siendo acotado, la participación ciudadana es limitada y solo en algunas experiencias puntuales la sociedad civil interviene en la definición de políticas públicas.

De este modo, aparecen asuntos de interés público sobre los que los gobiernos locales difícilmente pueden decidir, relacionados a la expansión de las ciudades; la localización de la vivienda social; la movilización, accesibilidad y conectividad; la disponibilidad de infraestructura urbana; conjuntamente a la necesidad de salvaguardar el patrimonio natural y los ecosistemas de gran importancia ambiental, los ambientes urbanos ubicados en los oasis mendocinos.

En consecuencia, el urbanismo sin planificación del área metropolitana, carente de responsabilidad, destructor simultáneo de lo rural, lo natural y lo urbano, ignorante del carácter limitado y limitante del suelo, provocó una realidad confusa en la que el espacio, en lugar de construirse, fue ocupado profusamente, con escasas conexiones entre la actividad y su soporte físico (AA.W., 2007).

En términos generales, ante el conjunto de problemáticas que se presentan en el Gran Mendoza, se carece de un esquema de gestión articulada que promueva un desarrollo local integral, sostenible e inclusivo.Así, la concertación multiactoral y estratégica asoma, en algunas experiencias, en la etapa inicial de procesos de desarrollo local, más precisamente en la realización de foros de diagnósticos, firmas del acta acuerdo de apoyo e incluso conformación de espacios institucionales, pero que posteriormente no implica una participación activa, continua y sostenible.

Asimismo, los procesos encarados aún no se traducen en una mejora significativa de las condiciones de desigualdad y fragmentación de las localidades. Problemáticas cuyo abordaje continúa fuertemente ligado a programas de origen provincial, 
nacional e, incluso, internacional, sin lograr madurar un proyecto endógeno en el cual prevalezcan las decisiones concertadas de los actores locales por sobre las decisiones y los impactos externos que tienen incidencia en el desarrollo del territorio.

Por consiguiente, las respuestas son soluciones coyunturales, puntuales y jurisdiccionales, inclusive superpuestas, en muy pocas ocasiones coordinadas, integradas o intergubernamentales, lo cual evidencia la ausencia de una visión integral del área metropolitana del Gran Mendoza como una unidad y de sus problemáticas estructurales, en todos los niveles.

Situaciones que repercuten en la gobernabilidad de la ciudad, como capacidad para orientar los procesos de configuración y funcionamiento urbanos, tanto respecto de los bienes privados y públicos materiales, suelo, viviendas, espacios públicos, tránsito, infraestructura vial, servicios, etc.

En síntesis, el área metropolitana es un ámbito políticamente fragmentado, frente a un espacio urbano compartido que obliga a distintos actores involucrados a negociar y llegar a acuerdos para la construcción de infraestructura, la provisión de servicios, las políticas de ordenamiento, etc.

Sin embargo, es importante reconocer que, pese a las dificultades y limitaciones señaladas, los gobiernos locales están conquistando logros relevantes: mayor coordinación interinstitucional, reconstrucción de la confianza hacia la acción administrativa local, recuperación de vínculos, formación de equipos técnicos locales, mayor transparencia, implementación de sistemas de información, diagnósticos locales que brindan un conocimiento sistematizado de la realidad local, articulación intermunicipal, aporte privado a iniciativas públicas o concertadas.

Ahora bien, desde el año 2006 cambia, progresiva y alentadoramente, el cuadro de situación político, a partir del mayor involucramiento de actores locales referentes de distintos sectores académicos, científicos, técnicos, profesionales u otros de la sociedad civil y vecinos. Se suman en una acción social muy participativa, motivados por el común objetivo de favorecer un modelo de desarrollo sostenible de Mendoza, frente a la posibilidad de que se sancionara una normativa de ordenamiento territorial que, en definitiva, legalizaría el consumo irracional, acelerado y abusivo del suelo.

En toda política pública de desarrollo local, la disposición a la cooperación supone la identificación de competencias, responsabilidades, potencialidades y roles de los distintos actores y la creación de las condiciones apropiadas para que la interacción entre ellos redunde en beneficios colectivos.

Se considera que dichas condiciones se manifiestan en el espacio de discusión que se abrió en torno a la elaboración y sanción de la Ley Provincial de Ordenamiento Territorial y Usos del Suelo $n^{\circ}$ 805 I, finalmente sancionada en el año 2009 de acuerdo a las propuestas elaboradas de forma colectiva. Asimismo, en lo que se considera una innovación institucional importante, se institucionaliza el espacio concertador durante la implementación de la ley que prevé instancias participativas para la planificación del desarrollo y ordenamiento del territorio, incluido un plan metropolitano integrado.

La norma, garante de una mejor calidad de vida de los ciudadanos, en congruencia con los principios de equidad social y equilibrio territorial, afirma la direc- 
ción del proceso de crecimiento de las localidades en base a habilidades técnicas y sociales.

De este modo, el desarrollo del territorio se basará en el conocimiento adecuado del contexto natural y socioeconómico local y sus potencialidades; reconocimiento de la importancia de los factores económicos y extraeconómicos; capacidad de identificación y asociación con actores y líderes locales; impulso permanente para la creación del entorno innovador territorial; formación de una visión colectiva de futuro; establecimiento de objetivos coherentes y realistas; vinculación de esa visión de largo plazo con las actuaciones concretas de mediano y corto plazo; control y evaluación continuados del proceso de desarrollo, entre otros aspectos.

Como parte del modelo de institucionalidad fijada por la ley, se ha conformado el Consejo de Estado, integrado por representantes de las instituciones académicas y científicas, organismos públicos y organizaciones de la sociedad civil, que tiene como función asistir al poder ejecutivo en la elaboración y revisión periódica del Plan Estratégico de Desarrollo de la Provincia de Mendoza. Este último es el instrumento de planificación y ejecución que establecerá un modelo de desarrollo al cual deberán compatibilizarse los diferentes planes sectoriales, ambientales y de ordenamiento territorial, provincial y municipal, bajo una estrategia integradora, y con base en la integración y participación de organizaciones, áreas y sociedad en general.

Por consiguiente, la norma establece guías conceptuales y metodológicas para la toma de decisiones de desarrollo urbano de los gobiernos locales y provincial, que reorienten el crecimiento anárquico y los desequilibrios territoriales que perjudican el medio ambiente y la calidad de vida de los ciudadanos. Es ilustrativo el ya mencionado proceso de reforma del Código de Edificación de la ciudad de Mendoza, que debe garantizar pautas de planificación urbana consensuada e incluyente de la consideración del área metropolitana.

\section{Reflexiones finales}

Más allá de las discrepancias, los debates, las discusiones, los estudios, los aportes, las decisiones y las acciones considerados, son signos de los cambios observados en cuanto a las visiones del modelo de desarrollo urbano deseado y de las capacidades requeridas por los distintos actores para una gestión pública urbana integral, metropolitana, sostenible y democrática.

Tal como se afirmara inicialmente, los procesos de construcción de espacios públicos de discusión y compromiso cívico, formas de constitución de actores políticos, de organización y articulación innovadoras entre el Estado y la sociedad civil, resultan tan o más importantes, que el contenido genérico de las políticas públicas. En este sentido, actores públicos y privados valoran elementos sustantivos de un renovado despliegue de capital social local para elegir y hacer valer su visión del desarrollo, para diseñar su destino y participar de las decisiones que lo orientan. 
Mientras que la dispersión, fragmentación y segregación urbanas, incitadas por fuerzas globales y favorecidas por intereses locales, supuso la desconexión del tejido social y modificó el sentido que tiene la ciudad como una civis; en los últimos años se percibe un fortalecimiento de las relaciones horizontales entre las personas, las instituciones y el territorio.

De forma simultánea, los actores asumen la realidad local como una construcción compleja, a la vez, e inseparablemente, material y simbólica, en la definición de políticas públicas de desarrollo integral, con impacto en los aspectos objetivos de los territorios y subjetivos de las sociedades. Así, anhelan un desarrollo urbano moderno, eficiente, renovador de espacios deprimidos, pero preservador del medio ambiente, consciente de los límites físicos y ambientales del avance descontrolado y reafirmante de la específica y muy característica identidad mendocina.

Para lo cual, es preciso consolidar el proceso de empoderamiento de los gobiernos locales, en un esquema históricamente centralista que ha concentrado funciones en el poder ejecutivo nacional. La cercanía de la administración local con el ciudadano y sus expectativas concretas, ha impuesto a los municipios deberes cuya satisfacción genera grados de confianza difíciles de alcanzar de manera distante, como asumir el rol de propulsor de estrategias de desarrollo mediante la movilización de recursos propios y la articulación público-privada.

Finalmente, se deja abierta la pregunta: ¡la intervención de la gestión pública, fortalecida por la acción colectiva y el compromiso activo multiactoral, concretará cambios sustanciales determinantes de un crecimiento planificado, sostenible y democrático, o bien mantendrá el carácter subsidiario orientador del mejor modelo de desarrollo posible? Las respuestas llegarán en la medida que se manifiesten logros de la Mendoza acordada recientemente en los Ejes Estratégicos del Plan Estratégico de Desarrollo Provincial Mendoza 2030.

\section{Referencias bibliográficas}

AA.VV. Universidad Nacional de Cuyo. (2007). Diagnóstico de la realidad territorial y objetivos para un modelo deseado de provincia. Mendoza: Universidad Nacional de Cuyo.

Arboit, M., Pastor, G. y de Rosa, C. (20I0). Impactos energético-ambientales previsibles de la implementación de las reformas al Código Urbano y de Edificación propuestas por la Municipalidad de Mendoza en Argentina. Cuzco: IV Conferencia Latino Americana de Energía Solar y XVII Simposio Peruano de Energía Solar, del I al 5 de noviembre de 2010.

Ascher, F. (200I). Les nouveaux príncipes de l'urbanisme. La Tour d'Aigues: Editions de l'Aube.

Ávila, H. (200I). Ideas y planteamientos teóricos sobre los territorios periurbanos. Las relaciones campo-ciudad en algunos países de Europa y América. México: Investigaciones Geográficas. Boletín del Instituto de Geografía 45 (s. n.). <http://redalyc. uaemex.mx/src/inicio/ArtPdfRed.jsp?iCve=56904508\&iCveNum=3II0> (23 de octubre de 2007). 
Barreiro, F. (2007). Territorios virtuosos para el desarrollo humano. Competitividad, cohesión social y ciudadanía en el desarrollo local. II Encuentro Latinoamericano. Retos del Desarrollo Local. Gestión Innovadora de Territorios. Ecuador: Oficina de Investigaciones Sociales y del Desarrollo (OFIS).

Boisier, S. (2003). El desarrollo en su lugar. El territorio en la sociedad del conocimiento. Santiago de Chile: Mimeo.

Borja, J. (2003). La ciudad conquistada. Madrid:Alianza.

Bradford, N. (2003). Des villes et des collectivités qui fonctionnent: pratiques innovatrices,politiques habilitantes. Ottawa: Canadian Policy Research Network

Bragagnini, S. (2009). Una propuesta para orientar el desarrollo de la ciudad. Infoguía de la Arquitectura. Mendoza: Colegio de Arquitectos de Mendoza.

Brugué, Q., Gomá, R. y Subirats, J. (2002). “Conclusiones. La gobernabilidad de las ciudades y los territorios en la sociedad de las redes". En Subirats, J. (coord.) Redes, Territorios y Gobierno. Nuevas respuestas locales a los retos de la globalización. Barcelona: Diputación de Barcelona. Xarxa de municipis. Colección Territorio y gobierno: visiones, $\mathrm{n}^{\circ} \mathrm{I}$.

Camagni, R., Gibelli, M. y Rigamonti, P. (2002). I costi collettivi della città dispersa. Firenza: Alinea.

Castells, M. (1999). La cuestión urbana. México: Siglo XXI Editores.

Castells, M. (200I). La era de la información. Vol. I: La sociedad red. Madrid: Alianza Editorial.

Centro de Tránsito y Transporte (2009). Estudio integral del sistema de transporte urbano de pasajeros del Gran Mendoza. Mendoza: Facultad de Ingeniería, Universidad Nacional de Cuyo.

Clementi, A., Dematteis, G. y Palermo, P. (eds. coords.) (1996). Le forme del territorio italiano.Vol. I. Roma: Laterza.

Consejo Asesor Permanente (2006). Marco estratégico Mendoza 20 I 2. Mendoza: Universidad Nacional de Cuyo.

Cuenya B, Fidel C. y Herzer H. (coords.) Fragmentos Sociales. Problemas urbanos de la Argentina. Buenos Aires: Siglo XXI.

De Mattos, C. (2002). Transformación de las ciudades latinoamericanas. ¿Impactos de la globalización? Santiago de Chile: EURE vol. 28 n 85 Santiago, diciembre 2002.

De Mattos, C. (2007). Modernización capitalista y revolución urbana en América Latina: cinco tendencias genéricas. Seminario Internacional "La globalización neoliberal y la planeación urbano-regional: perspectivas en América Latina”, 23 y 24 agosto de 2007. Medellín: Universidad Nacional de Colombia, pp. I-3I.

Dematteis, G. (1998). "Suburbanización y periurbanización. Ciudades anglosajonas y ciudades latinas”. En Monclus, F. J. (ed.) La ciudad dispersa. Suburbanización y nuevas periferias. Barcelona: Centre de Cultura Contemporánia de Barcelona.

Dematteis, G. (2002). “De las regiones-área a las regiones-red. Formas emergentes de gobernabilidad regional”. En Subirats, J. (ed.), Redes, territorios y gobierno. Nuevas respuestas globales a los retos de la globalización. Barcelona: Diputació de Barcelona.

Dematteis, G. (2006). “En la encrucijada de la territorialidad urbana”. En Revista Bitácora Urbano Territorial, n 10, Bogotá: Universidad Nacional de Colombia, pp. 53-63.

Dirección de Estadísticas e Investigaciones Económicas, Gobierno de Mendoza, $<w w w$.deie.mendoza.gov.ar>. 
European Environment Agency (EEA). Urban Sprawl in Europe, 2006. Copenhague: EEA. Fleury, S. (2005). La ciudad de los ciudadanos. Congreso Internacional del CLAD sobre la Reforma del Estado y de la Administración Pública, -|8-2I de Octubre de 2005. Santiago de Chile: CLAD.

Furlani de Civit, M. E. (1999). Problemas urbanos de una metrópoli regional: Mendoza. Primer Encuentro Internacional Humboldt. Noviembre de 1999. Buenos Aires. Recuperado el 25 de noviembre de 2009, de: wwww.centrohumboldt.org.ar Gallicchio, E. (2004). El desarrollo local en América Latina. Estrategia política basada en la construcción de capital social. Uruguay: Programa de Desarrollo Local, CLAEH.

García Schilardi, M. E. (20I0). Estructura de recorridos del transporte público urbano de pasajeros. Mendoza: Plataforma de Información de Políticas Públicas, Universidad Nacional de Cuyo.

Giampino,A. (2010).“¿Metrópolis dispersas?”. En Cuadernos de Investigación Urbanística $\mathrm{n}^{\circ}$ 72, setiembre/octubre 2010. Madrid: Instituto Juan de Herrera.

Gudiño de Muñoz, M. (2000). Implicancias territoriales del proceso de transformación económica iniciado en la década de los noventa. Caso: Mendoza, República Argentina. Alemania: ISPA, Universidad de Vechta.

Hayes, Ch. (1976). The Dispersed City. Chicago:The University of Chicago.

Instituto de Desarrollo Industrial, Tecnológico y de Servicios de Mendoza (IDITS) (2008). Parque, Áreas y Zonas Industriales de la Provincia de Mendoza. Mendoza: IDITS.

Instituto Nacional de Estadísticas y Censos. Censo 2010. <www.censo2010.indec. gov.ar>.

Méndez, R. (2008). Conocimiento e innovación para el desarrollo de ciudades intermedias. IX Coloquio de Geografía Urbana (AGE) (en proceso de publicación).

Pírez, P. (200I). “Cuestión metropolitana y gobernabilidad urbana en la Argentina”. En Vázquez Barquero, A. y Madoery, O. (comps.). Transformaciones globales, instituciones y políticas de desarrollo local. Buenos Aires: Edit. Homo Sapiens.

Pírez, P. (2008). “Gobernabilidad metropolitana en la Argentina”. En Badía, G. y Carmona, R. (comps.) La gestión local en Argentina: situación y perspectivas. Universidad Nacional de General Sarmiento, Los Polvorines, Buenos Aires.

Programa de las Naciones Unidas para el Desarrollo (PNUD). (20I0). Informe desarroIlo humano en Argentina: trayectos y nuevos desafios. Buenos Aires. PNUD.

Programa de las Naciones Unidas para el Desarrollo (PNUD). (2009). Segregación residencial en Argentina. Buenos Aires. Buenos Aires. PNUD.

Rofman, A. y Villar, A. (comps). (2006). Desarrollo local. Una revisión crítica del debate. Buenos Aires: Ed. Espacios.

Rotiman, S. (2000). Transformaciones urbanas en los 90: los barrios cerrados del área metropolitana de Mendoza. Buenos Aires: IV Jornadas de Sociología. UBA.

Rueda, S. (2007). La ciudad compacta y diversa frente a la conurbación difusa. Recuperado el 5 de setiembre de 2008, de:<http://habitat.aq.upm.es/cs/p2/a009.html>.

Sassen, S. (2007). Sociología de la globalización. Buenos Aires: Katz Editores.

Schmidt, I. (2007). “El Transporte público urbano asegura la inclusión social”. Informe digital metropolitano, octubre de 2007, $\mathrm{n}^{\circ} 43$. Recuperado el 13 de mayo de 2009, de: <www.metropolitana.org.ar/idm/idm_43/idm_43_columna.html>. 
Secretaría de Medio Ambiente de Mendoza (2009, 2010a). Informe Ambiental 2009 e Informe Ambiental 20 I0. Gobierno de Mendoza. Disponible en <www.ambiente.mendoza.gov.ar/>.

Secretaría de Medio Ambiente de Mendoza (20l0b). Plan estratégico de desarrollo de Mendoza. Gobierno de Mendoza. Disponible en <http://www.planestrategico. mendoza.gob.ar/>.

Sen, A. (2000). Desarrollo y libertad. Barcelona: Editorial Planeta.

Subirats, J., Knoepfel, P., Larrue, C. y Varone, F., (2008). Análisis y gestión de políticas públicas. Barcelona: Ed. Ariel.

Tomassini, L. y Kliksberg, B. (2000). Capital social y cultura: claves estratégicas para el desarrollo. Buenos Aires: Banco Interamericano de Desarrollo, FCE.

Valpreda, E. C. (2008). Amenazas naturales de origen hídrico en el centro oeste árido de Argentina. Caso de estudio: Gran Mendoza y Gran San Juan. Mendoza: Instituto CIFOT, FFyL, UNCuyo y IANIGLA, CRICyT.

Van den Berg, L. (1982). Urban Europe.A Study of Growth and Decline. Oxford: Pergamon Press. 